\title{
Impact of autologous platelet rich plasma use on postoperative acute kidney injury in type $A$ acute aortic dissection repair: a retrospective cohort analysis
}

Jiaqi Tong ${ }^{1,2+}$, Liang Cao ${ }^{2,3+}$, Liwei $\mathrm{Liu}^{1,2+}$ and Mu Jin ${ }^{1,2^{*}}$ (D)

\begin{abstract}
Background: Perioperative coagulopathy and blood transfusion are common in patients undergoing Stanford type A acute aortic dissection (AAD) repair. The autologous platelet-rich plasmapheresis (aPRP) technique is a blood conservation approach to reduce blood transfusions and morbidity in patients at high risk of bleeding. The purpose of this study was to analyze the effect of aPRP on outcomes, especially in postoperative acute kidney injury (post$A K I)$, in patients undergoing AAD surgery.

Methods: Six hundred sixty patients were divided into aPRP and non-aPRP groups according to aPRP use. The primary endpoint was the difference in the incidence of post-AKI between two groups. The secondary endpoints were risk factors for post-AKI and to assess clinical outcomes. The risk factors associated with post-AKI were calculated, and all outcomes were adjusted by propensity-score matching analysis.

Results: A total of 272 patients (41.2\%) received aPRP, whereas 388 were in the non-aPRP group. Compared to non-aPRP group, the occurrence of post-AKl increased by $14.1 \%(p=0.002)$ and $11.1 \%(p=0.010)$ with and without propensity adjustment in the aPRP group, respectively. The aPRP group required fewer intraoperative transfusions $(p<0.05)$ and shortened the duration of mechanical ventilation $(p<0.05)$ than those in the non-aPRP group. Multiple regression analyses showed that aPRP (odds ratio: 1.729, 95\% confidence interval: 1.225-2.440; $p<0.001$ ) was one of the independent risk factors for post-AKl.

Conclusions: The use of aPRP significantly reduced intraoperative blood transfusions and decreased postoperative mortality-adjusted mechanical ventilation. However, aPRP use was independently associated with an increased hazard of post-AKI after adjusting for confounding factors.
\end{abstract}

Keywords: Autologous platelet rich plasma, Acute aortic dissection, Acute kidney injury

\footnotetext{
* Correspondence: jinmu0119@hotmail.com

${ }^{\dagger}$ Jiaqi Tong, Liang Cao and Liwei Liu contributed equally to this work.

'Department of Anesthesiology, Beijing Friendship Hospital, Capital Medical

University, No. 95 Yongan Rd, Xicheng District, Beijing City 100050, China

${ }^{2}$ Department of Anesthesiology, Beijing Anzhen Hospital, Capital Medical University, Beijing Institute of Heart Lung and Blood Vessel Diseases, and

Beijing Engineering Research Center of Vascular Prostheses, No. 2 Anzhen Rd, Beijing 100029, China

Full list of author information is available at the end of the article
}

C C The Author(s). 2021 Open Access This article is licensed under a Creative Commons Attribution 4.0 International License, which permits use, sharing, adaptation, distribution and reproduction in any medium or format, as long as you give appropriate credit to the original author(s) and the source, provide a link to the Creative Commons licence, and indicate if changes were made. The images or other third party material in this article are included in the article's Creative Commons licence, unless indicated otherwise in a credit line to the material. If material is not included in the article's Creative Commons licence and your intended use is not permitted by statutory regulation or exceeds the permitted use, you will need to obtain permission directly from the copyright holder. To view a copy of this licence, visit http://creativecommons.org/licenses/by/4.0/. The Creative Commons Public Domain Dedication waiver (http://creativecommons.org/publicdomain/zero/1.0/) applies to the data made available in this article, unless otherwise stated in a credit line to the data. 


\section{Introduction}

Stanford type A acute aortic dissection (AAD) is characterized by the rapid development of an intimal flap separating the false and true lumen, blood flow through the nonendothelialized false lumen, and turbulence, which triggers activation of the platelet and coagulation/fibrinolytic system [1, 2]. Moreover, surgery and cardiopulmonary bypass (CPB)-induced coagulation factor consumption and excessive fibrinolysis and platelet activation promote perioperative blood loss and blood product transfusion [3,4]. Thus, various blood conservation approaches have been applied to improve blood conservation [5-7]. The use of aPRP in cardiac surgery is beneficial for those at high risk of bleeding and reduces blood transfusions during AAD surgery in those undergoing $\mathrm{CPB}$ and hypothermic circulatory arrest [810]. However, volume replacement and unstable hemodynamics are always along with aPRP harvest process, which is potential risk factors of postoperative acute kidney injury [11]. The purpose of this study was to analyze the effect of aPRP on post-AKI in patients undergoing $\mathrm{AAD}$ surgery.

\section{Materials and methods Patient population}

This study was approved by the Ethics Committee of the Beijing Anzhen Hospital Clinical Research (Beijing, China), and consent was waived because of the retrospective data collection. Patients with Stanford type A AAD were eligible if they were between 18 and 75 years of age and were suitable for emergency surgery. A total of 1013 consecutive patients' records were collected between January 2013 and June 2017. Patients who had severe cardiac tamponade, cardiogenic shock, cardiac arrest, or severe systolic hypotension were excluded from the analysis for both groups. Exclusion criteria are shown as a flow diagram (Fig. 1). Patients were divided into two groups: aPRP group and non-aPRP group.

\section{Study endpoint}

The primary endpoint of this study was the difference in the incidence of post-AKI after Stanford type A AAD surgery between aPRP group and non-aPRP group. The secondary endpoints were risk factors for post-AKI and to assess clinical outcomes. Clinical outcomes included perioperative blood product transfusions, in-hospital mortality, time to mechanical ventilation, intensive care unit length of stay, and gastrointestinal tract bleeding. Post-AKI was defined as AKI within postoperative $48 \mathrm{~h}$ based on Kidney Disease Improving Global Outcomes (KDIGO) criteria [12].

\section{Surgical technique}

After routine anesthesia and intubation, general anesthesia was maintained with intravenous sufentanil, propofol, and neuromuscular blockade drugs. Sun's surgical technique has been previously detailed [13, 14]. In brief, right axillary artery cannulation was used for cardiopulmonary bypass $(\mathrm{CPB})$ and unilateral selective antegrade cerebral perfusion under moderate hypothermic circulatory arrest at $25^{\circ} \mathrm{C}$. The surgical procedure involved the deployment of a frozen elephant trunk, Cronus (MicroPort Medical, Shanghai, China), into the descending aorta, followed by total arch replacement with a 4-branched vascular graft (Maquet Cardiovascular, Wayne, NJ). Aortic valve or root procedures and concomitant surgeries, such as coronary artery bypass grafting (CABG), were performed during the cooling phase. Blood products were transfused to maintain hemoglobin level $>7 \mathrm{~g} / \mathrm{L}$ at weaning from $\mathrm{CPB}$, and to correct coagulopathy by thromboelastogram and clinical parameters.

\section{aPRP harvest technique}

aPRP was collected from a large-bore central venous access by gravity drainage and an autologous transfusion system (Sorin-Xtra, Milan, Italy) before the administration of heparin and reinfused after the reversal of heparin. Approximately $15 \mathrm{~mL} / \mathrm{kg}$ of whole blood was collected. A balanced salt solution (Ringer's lactate) were used to maintain intravascular volume and hemodynamic stability during the aPRP harvest, as well as continuous IV infusion noradrenaline or dopamine. No cases of hemodynamic instability were noted during aPRP collection.

\section{Statistical analysis}

All data analyses were performed with SPSS 24.0 (IBM, Armonk, NY, USA). Quantitative variables are presented as the mean \pm standard deviation or median (interquartile range), and categorical variables are presented as frequencies or percentages. Multiple regression analyses were used to determine the independent factors of postAKI. Propensity-score matching was performed by logistic regression for variable adjustment, and the variables of age, body mass index (BMI), preoperative $\mathrm{SCr}$, and duration of surgery were used as covariates. Then patients were matched 1:1 based on their propensity scores, with a fixed caliper width of 0.1. All statistical tests were two-sided, and $p<0.05$ was considered statistically significant.

\section{Results}

Baseline characteristics

According to the inclusion and exclusion criteria, a total of 660 patients undergoing Stanford type A AAD 


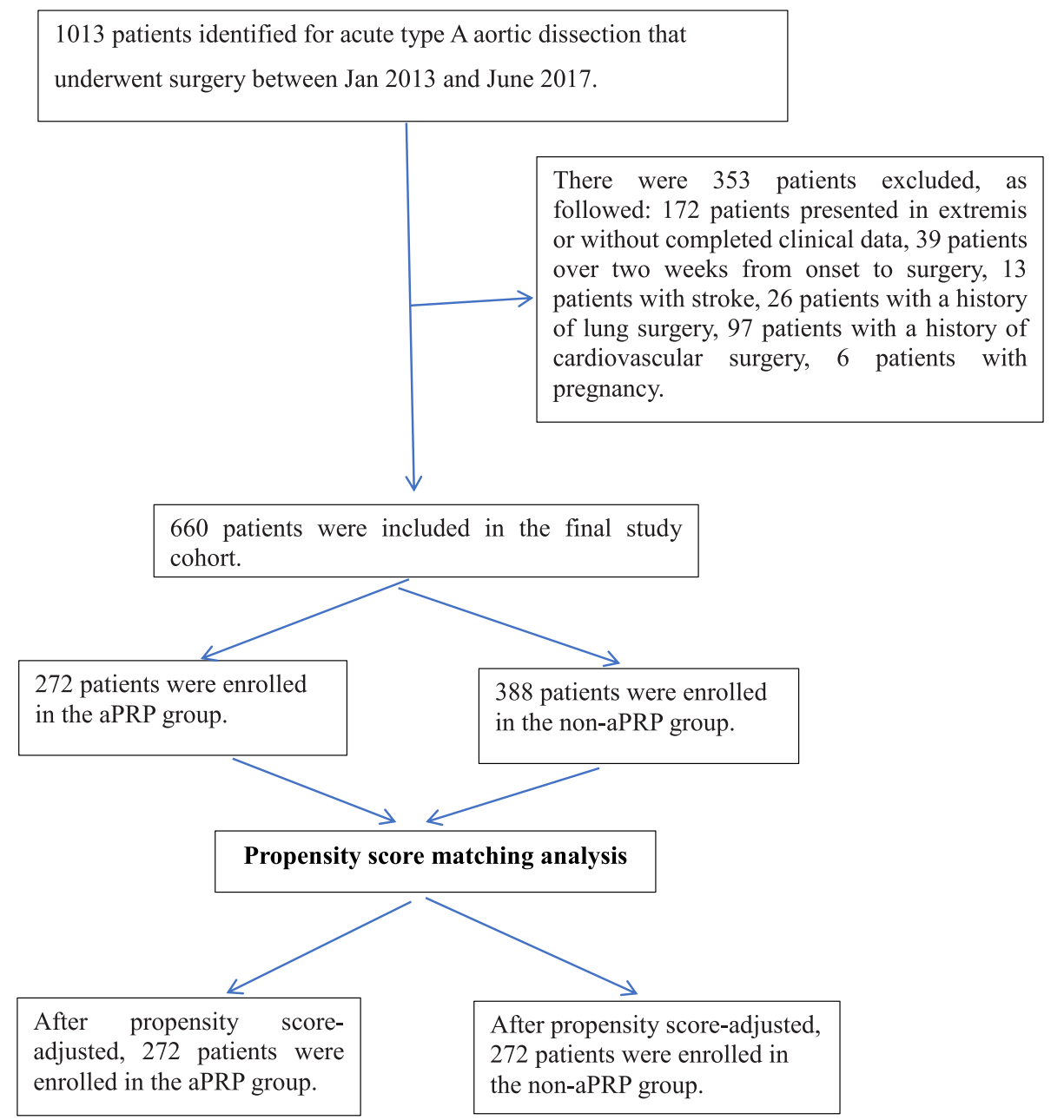

Fig. 1 Flow diagram

surgery were ultimately included in this study. The flow diagram is presented in Fig. 1. In the aPRP group, 272 patients (41.2\%) received aPRP, whereas 388 patients were in the non-aPRP group. The mean amount of aPRP collected was $594 \pm 331 \mathrm{~mL}$, and the mean amount of red blood cells was $428 \pm 243 \mathrm{ml}$. The aPRP and nonaPRP groups demonstrated the differences of age, BMI, history of smoking, preoperative mean blood pressure, hemoglobin, $\mathrm{PLC}$ and preoperative $\mathrm{SCr} \quad(p<0.005)$ (Table 1).

\section{Intraoperative}

Duration of surgery was more longer in the aPRP group than in the non-aPRP group. The aPRP group required fewer intraoperative transfusions $(p<0.001)$ and more intravenous crystalloid $(p<0.05)$ than the non-aPRP group. Adjustment for propensity score did not materially alter the clinical effects and statistical differences for these intraoperative blood products and intravenous solution.

\section{Postoperative outcomes}

Postoperative outcomes are shown in Table 2. The primary association of aPRP with unadjusted postoperative complications involved less mortality-adjusted mechanical ventilation $(p=0.029)$ and in-hospital mortality $(p=0.001)$. Upon propensity score adjustment, in-hospital mortality was similar in both groups $(p=0.904)$. The occurrence of post-AKI was greater in the aPRP group, both without and with propensity adjustment $(14.1 \%(p=0.002)$ and $11.1 \%(p=0.010)$, respectively). Multiple regression analyses of these variables showed that aPRP (odds ratio [OR]: 1.729, 95\% confidence interval [CI]: 1.225-2.440; $p<0.001$ ), postoperative Scr (OR: 1.010, 95\% CI: 1.006-1.014; $p<0.001$ ) and postoperative LAC (OR: $1.104,95 \%$ CI: $1.047-1.164 ; p<0.001)$ were significantly associated with post-AKI with adjustment for factors (Table 3). The AUROC (receiver operating characteristic) of this multivariable binary logistic regression analysis was 0.790 (95\% CI, 0.754-0.825). 
Table 1 Perioperative variables in the non-aPRP group and aPRP group

\begin{tabular}{|c|c|c|c|}
\hline Clinical variables & Non-aPRP Group $(n=388)$ & $\operatorname{aPRP} \operatorname{Group}(n=272)$ & $P$ Value \\
\hline Age (year) & $49.29 \pm 10.60$ & $47.52 \pm 9.77$ & 0.030 \\
\hline Males, n (\%) & $305(78.4)$ & $230(84.6)$ & 0.067 \\
\hline Height (cm) & $172.05 \pm 7.51$ & $171.49 \pm 8.02$ & 0.359 \\
\hline Weight (kg) & $77.02 \pm 13.16$ & $78.8 \pm 13.20$ & 0.073 \\
\hline $\mathrm{BMI}\left(\mathrm{kg} / \mathrm{M}^{2}\right)$ & $25.97 \pm 3.75$ & $26.75 \pm 3.70$ & 0.009 \\
\hline History of smoking, n (\%) & $137(35.2)$ & $120(44.1)$ & 0.023 \\
\hline History of hypertension, $\mathrm{n}(\%)$ & $294(75.8)$ & $199(73.2)$ & 0.448 \\
\hline History of DM, n (\%) & $18(4.6)$ & $13(4.8)$ & 0.933 \\
\hline Time from onset of symptoms to surgery (d) & $2(1,4)$ & $2(1,4)$ & 0.768 \\
\hline \multicolumn{4}{|l|}{ preoperative } \\
\hline LVEF (\%) & $60.22 \pm 6.52$ & $60.58 \pm 6.302$ & 0.490 \\
\hline LVEDd (mm) & $50.76 \pm 8.71$ & $49.888 \pm 7.8517$ & 0.195 \\
\hline EUROSCORE & $5(4.5,5)$ & $5(5,5)$ & 0.408 \\
\hline HR (beats/min) & $80 \pm 15$ & $80 \pm 15$ & 0.334 \\
\hline $\mathrm{MBP}(\mathrm{mm} \mathrm{Hg})$ & $89 \pm 18$ & $85 \pm 22$ & 0.014 \\
\hline $\mathrm{Hb}(\mathrm{g} / \mathrm{L})$ & $12.68 \pm 2.63$ & $13.91 \pm 4.14$ & 0.001 \\
\hline WBC $\left(10^{9} / \mathrm{L}\right)$ & $10.91 \pm 4.11$ & $11.38 \pm 3.72$ & 0.135 \\
\hline $\operatorname{PLC}\left(10^{9} / \mathrm{L}\right)$ & $151 \pm 76$ & $171 \pm 64$ & 0.001 \\
\hline LAC (mmol/L) & $1.52 \pm 0.95$ & $1.56 \pm 0.87$ & 0.549 \\
\hline $\mathrm{SCr}(\mathrm{umol} / \mathrm{L})$ & $102.9 \pm 53.1$ & $82.6 \pm 37.6$ & $<0.001$ \\
\hline PT (second) & $12.74 \pm 2.29$ & $12.81 \pm 2.06$ & 0.727 \\
\hline PTA(100\%) & $87.03 \pm 14.44$ & $84.67 \pm 14.67$ & 0.128 \\
\hline APTT (second) & $32.83 \pm 11.51$ & $31.70 \pm 6.76$ & 0.211 \\
\hline $\mathrm{FlB}(\mathrm{g} / \mathrm{L})$ & $3.30 \pm 1.49$ & $3.21 \pm 1.56$ & 0.571 \\
\hline $\mathrm{FDP}(\mathrm{mg} / \mathrm{L})$ & $18.65(9.01,31.45)$ & $19.2(10.2,35.65)$ & 0.329 \\
\hline D-D (ug/L) & $1581(850,2976)$ & $1836(808,2719)$ & 0.660 \\
\hline INR & $1.09(1.03,1.18)$ & $1.11(1.04,1.19)$ & 0.192 \\
\hline \multicolumn{4}{|l|}{ Intraoperative } \\
\hline With CABG & $13(5.2)$ & $16(6.5)$ & 0.537 \\
\hline Duration of surgery (min) & $465 \pm 99$ & $492 \pm 105$ & 0.001 \\
\hline Duration of CPB (min) & $271.49 \pm 172.64$ & $281.27 \pm 152.09$ & 0.453 \\
\hline Duration of Aortic cross-clamping (min) & $92.97 \pm 56.01$ & $86.95 \pm 54.77$ & 0.171 \\
\hline Lowest rectal temperature $\left({ }^{\circ} \mathrm{C}\right)$ & $25.21 \pm 2.13$ & $25.21 \pm 1.79$ & 0.966 \\
\hline Lowest nasopharyngeal temperature $\left({ }^{\circ} \mathrm{C}\right)$ & $22.46 \pm 6.02$ & $22.91 \pm 6.60$ & 0.363 \\
\hline Intravenous crystalloid (mL) & $2153 \pm 887$ & $2354 \pm 1133$ & 0.015 \\
\hline Allogeneic Red blood cells (units) & $0(0,4)$ & $0(0,3)$ & 0.012 \\
\hline Allogeneic blood Plasma (mL) & $200(0,600)$ & $0(0,400)$ & 0.001 \\
\hline${ }^{\mathrm{a} B l o o d}$ product transfused (ml) & $520(0,1040)$ & $375(0,975)$ & 0.014 \\
\hline Urine volume during surgery $(\mathrm{mL})$ & $1591 \pm 1073$ & $1643 \pm 863$ & 0.503 \\
\hline \multicolumn{4}{|l|}{ Postoperative } \\
\hline LVEF (\%) & $59.68 \pm 7.04$ & $59.59 \pm 6.57$ & 0.870 \\
\hline HR (beats/min) & $93 \pm 17$ & $94 \pm 16$ & 0.384 \\
\hline $\operatorname{MBP}(\mathrm{mmHg})$ & $88 \pm 19$ & $86 \pm 20$ & 0.20 \\
\hline $\mathrm{Hb}(\mathrm{g} / \mathrm{L})$ & $10.23 \pm 1.86$ & $10.42 \pm 1.57$ & 0.545 \\
\hline
\end{tabular}


Table 1 Perioperative variables in the non-aPRP group and aPRP group (Continued)

\begin{tabular}{|c|c|c|c|}
\hline Clinical variables & Non-aPRP Group $(n=388)$ & $\operatorname{aPRP} \operatorname{Group}(n=272)$ & $P$ Value \\
\hline WBC $\left(10^{9} / L\right)$ & $11.48 \pm 4.86$ & $12.15 \pm 4.57$ & 0.20 \\
\hline $\operatorname{PLC}\left(10^{9} / \mathrm{L}\right)$ & $106 \pm 51$ & $97 \pm 62$ & 0.14 \\
\hline $\mathrm{LAC}(\mathrm{mmol} / \mathrm{L})$ & $2.79 \pm 3.12$ & $3.97 \pm 3.93$ & $<0.001$ \\
\hline PT (second) & $13.77 \pm 4.45$ & $13.18 \pm 2.39$ & 0.080 \\
\hline PTA(100\%) & $82.81 \pm 15.72$ & $81.56 \pm 14.86$ & 0.442 \\
\hline APTT (second) & $32.63 \pm 7.13$ & $33.10 \pm 12.04$ & 0.628 \\
\hline $\mathrm{FIB}(\mathrm{g} / \mathrm{L})$ & $3.34 \pm 1.43$ & $3.39 \pm 1.97$ & 0.731 \\
\hline $\mathrm{FDP}(\mathrm{mg} / \mathrm{L})$ & $19(9.17,32.4)$ & $17.56(9.52,35.67)$ & 0.929 \\
\hline D-D (ug/L) & $1963(855,3046)$ & $1619(815,2841)$ & 0.510 \\
\hline INR & $1.12(1.04,1.24)$ & $1.14(1.06,1.24)$ & 0.323 \\
\hline $\mathrm{SCr}(\mathrm{umol} / \mathrm{L})$ & $118.58 \pm 72.59$ & $105.89 \pm 51.50$ & 0.011 \\
\hline \multicolumn{4}{|l|}{ Postoperative $24 \mathrm{~h}$} \\
\hline $\mathrm{SCr}(\mathrm{umol} / \mathrm{L})$ & $133.1 \pm 91.8$ & $115.2 \pm 66.6$ & 0.005 \\
\hline Seroma volume of drainage $(\mathrm{mL})$ & $1472 \pm 667$ & $1539 \pm 820$ & 0.263 \\
\hline \multicolumn{4}{|l|}{ Postoperative $48 \mathrm{~h}$} \\
\hline $\mathrm{SCr}(\mathrm{umol} / \mathrm{L})$ & $136.1 \pm 106.3$ & $122.3 \pm 98.2$ & 0.102 \\
\hline \multicolumn{4}{|l|}{ Postoperative $72 \mathrm{~h}$} \\
\hline $\mathrm{SCr}(\mathrm{umol} / \mathrm{L})$ & $113.4 \pm 93.7$ & $110.1 \pm 77.5$ & 0.737 \\
\hline
\end{tabular}

Figure 2 depicts perioperative $\mathrm{SCr}$ continuously increasing from preoperative to postoperative 3-day time points in the two groups $(p<0.001)$. We repeated measurements of perioperative $\mathrm{SCr}$ at each follow-up visit to characterize the changes in post-AKI over time in both groups. $\mathrm{SCr}$ levels increased and peaked at 2 days after surgery and then decreased until 3 days after surgery in all patients. There was no significant differences in treatment-time effects for perioperative $\mathrm{SCr}$ levels between both groups. However, in the first period (from preoperative to postoperative), there was a mean maximal increase in SCr of 15.6 and $28.1 \%$ in the nonaPRP and aPRP groups, respectively; in the last period (postoperative 2-3 days), there was a mean maximal decrease in $\mathrm{SCr}$ of 16.9 and $9.8 \%$ in the non-aPRP and aPRP groups, respectively.

\section{Discussion}

Theoretically, aPRP is less exposure of coagulation factors and platelets to the extra-circulation system to achieve blood conservation from the deleterious effects of CPB. The centrifugation device and autologous

Table 2 Postoperative complications compared between non-aPRP and aPRP groups

\begin{tabular}{|c|c|c|c|c|c|c|}
\hline \multirow[t]{2}{*}{ Variables } & \multicolumn{3}{|l|}{ Unmatched } & \multicolumn{3}{|c|}{ Propensity score-matched } \\
\hline & $\begin{array}{l}\text { Non-aPRP Group }(n= \\
388)\end{array}$ & $\begin{array}{l}\text { aPRP Group }(n= \\
272)\end{array}$ & $\begin{array}{l}P \\
\text { Value }\end{array}$ & $\begin{array}{l}\text { Non-aPRP Group }(n= \\
\text { 272) }\end{array}$ & $\begin{array}{l}\text { aPRP Group }(n= \\
272)\end{array}$ & $\begin{array}{l}P \\
\text { Value }\end{array}$ \\
\hline $\begin{array}{l}\text { Mortality-adjusted Mechanical } \\
\text { ventilation }(h)^{\mathrm{a}}\end{array}$ & $40(17,95)$ & $28(16,67)$ & 0.029 & $40(17,92)$ & $28(16,67)$ & 0.043 \\
\hline ICU length of stay $(h)^{a}$ & $45(23,90)$ & $43.5(21.5,95.5)$ & 0.439 & $40(22,82)$ & $43.5(21.5,95.5)$ & 0.368 \\
\hline Post-AKI, n (\%) & $152(39.2)$ & $145(53.3)$ & 0.002 & $115(42.2)$ & $145(53.3)$ & 0.010 \\
\hline CRRT, n (\%) & $11(2.8)$ & $25(9.2)$ & 0.013 & $10(3.8)$ & $25(9.2)$ & 0.015 \\
\hline Gl tract bleeding, n (\%) & $39(10.1)$ & $34(12.5)$ & 0.324 & $34(12.8)$ & $34(12.5)$ & 0.922 \\
\hline In-hospital mortality, n (\%) & $37(9.5)$ & $16(5.9)$ & 0.001 & $15(5.6)$ & $16(5.9)$ & 0.904 \\
\hline
\end{tabular}

${ }^{a}$ In-hospital Survivors; ICU Intensive care unit, CRRT Continuous renal replacement therapy, post-AKI Acute kidney injury within postoperative $48 \mathrm{~h}, \mathrm{Gl}$ Gastrointestinal; Other abbreviations are presented in Table 1 
Table 3 Risk factors for postoperative differences stage acute kidney injury after repair of acute Type A aortic dissection in the multivariate-adjusted model ${ }^{\mathrm{a}}(n=660)$

\begin{tabular}{llll}
\hline Variables & Post-AKI & & \\
\cline { 2 - 4 } & OR & $95 \%(\mathrm{Cl})$ & $P$ Value \\
\hline aPRP & 1.729 & $1.225-2.440$ & 0.002 \\
postoperative serum creatine (umol/L) & 1.010 & $1.006-1.014$ & $<0.001$ \\
Postoperative LAC (mmol/L) & 1.104 & $1.047-1.164$ & $<0.001$
\end{tabular}

$O R$ odds ratio, $\mathrm{Cl}$ confidence interval

a adjusted for male, age, BMI, Intravenous crystalloid, Blood product transfused, Duration of surgery, and History of smoking

transfusion system can be used to harvest and separate whole blood into red cell concentrate and aPRP fraction. The collected red cell is reinfused depended on hemoglobin concentration, and aPRP fraction is reinfusion after separation from $\mathrm{CPB}$ and reversal of anticoagulation.

Similar to prior reports $[8,10,15]$, we found the aPRP technique markedly reduced intraoperative allogeneic blood transfusion and shortened the duration of mechanical ventilation. For whole blood exposed to the $\mathrm{CPB}$ circuit, the patient's platelets were activated, and coagulation factors were consumed during $\mathrm{CPB}$. The use of aPRP can maintain normal platelet function, preserve plasma volume, and ultimately reduce transfusion. In previous studies, Zhou [8] and Han [15] presumed that the use of aPRP could ameliorate postoperative lung injury and shorten mechanical ventilation, possibly related to fewer allogeneic transfusions.

$\mathrm{AKI}$ is frequent as a severe complication following an operation for Type A AAD. According to KDIGO criteria, the reported incidence of post-AKI after thoracic aortic surgery is 53\% [16] and 77.6\% [17] in China. In this study, we found that there was a significantly lower incidence of post-AKI (45\%) compared with the results reported previously. In the present study, we defined post-AKI as AKI occurred within $48 \mathrm{~h}$ after surgery, which reduced the incidence of post-AKI and avoided other postoperative complications to confounding the effect of aRPR on renal function.

In this study, the use of aPRP was independently associated with an increased hazard of post-AKI. The main risk with aPRP harvest was hemodynamic fluctuation and hemodilution induced by acute hypovolemia and alternate fluid therapy. In the aPRP group, rapid fluid replacement therapy were required to maintain hemodynamic stability during aPRP collection. Total fluid volume for transfusion was higher in the aPRP group than in the non-aPRP group, which not related to post-AKI by Logistic analysis.

In this study, post-AKI development after type A acute aortic dissection repair was associated mainly with postoperative variables, such as postoperative serum

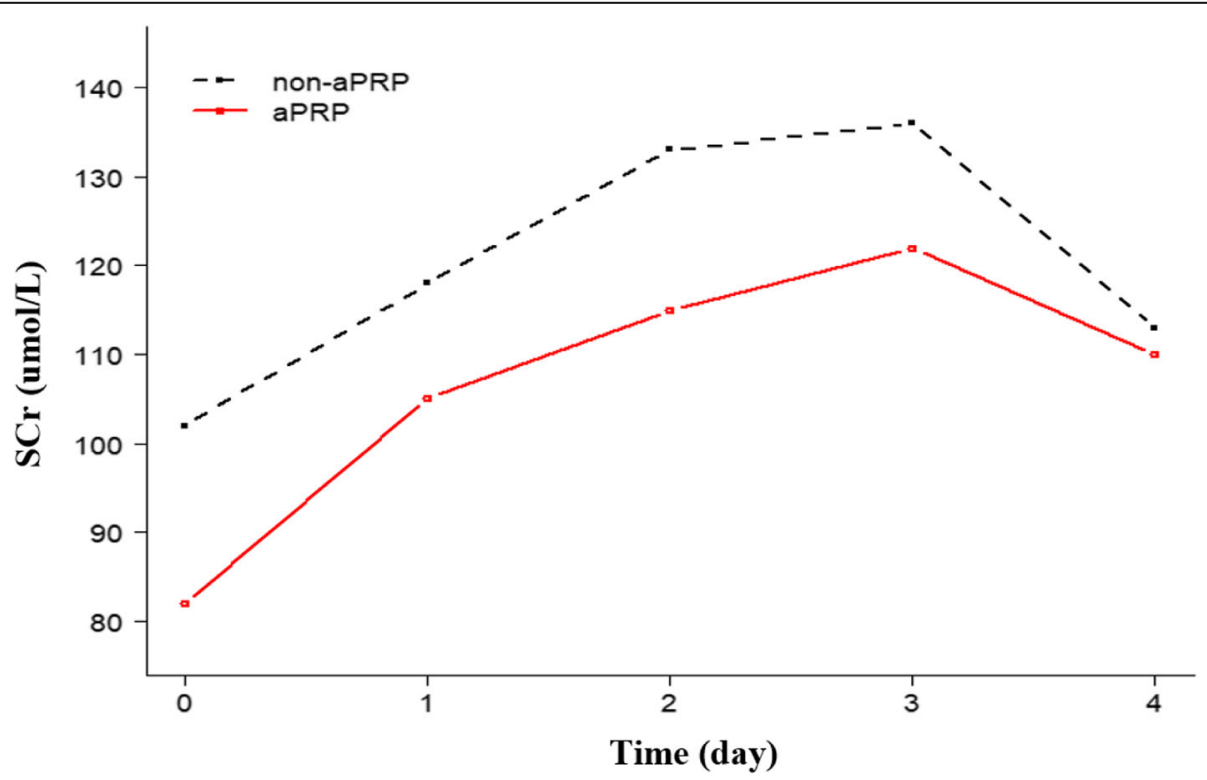

Fig. 2 Perioperative SCr changes from preoperative to postoperative 3-day time points in both groups. 0, preoperative; 1, postoperative; 2 , postoperative 1 day; 3 , postoperative 2 days; 4 , postoperative 3 days 
creatinine and lactate. Although novel biomarkers, such as neutrophil gelatinase-associated lipocalin and cystatin $\mathrm{C}$, have been identified as independent predictors of AKI and are superior to conventional biomarkers, $\mathrm{sCr}$ continues to be a more valuable and accepted tool for AKI diagnosis [18]. During surgery and $\mathrm{CPB}$, the kidneys may suffer from an imbalance between oxygen supply and oxygen needs that is associated with lactate production [19]. Higher serum lactate values, which are a surrogate marker of tissue hypoperfusion and imbalance of renal oxygen metabolism, were associated with the occurrence of postoperative AKI. In addition, lower hemoglobin induced by hemodilution during aPRP collection decreased oxygen delivery and was also associated with postoperative AKI [20].

The precise mechanism of aPRP on post-AKI has not been clarified. Thus, careful monitoring and management of hemodynamic and maintaining fluid balance by experienced anesthesiologists during aPRP harvest play a vital role in improving postoperative kidney function. In addition, there still are some questions to be addressed for the application of aPRP in future studies.

\section{Limitations}

This retrospective study has several limitations. The most important limitation was the difference in preoperative variables between groups and the possibility of selection bias due to the nonrandomized design. The preoperative characteristics of patients in the aPRP group were younger age, higher BMI values, lower levels of preoperative $\mathrm{SCr}$, and longer duration of surgery patients than those in the non-PRP group. The characteristics between the two groups could be adjusted to partially correct for these differences by propensityadjusted matching analysis. Additionally, preoperative renal malperfusion is an independent predictor for postoperative AKI [21]. Preoperative renal malperfusion also induced an increase in preoperative $\mathrm{SCr}$ values, which possibly led to bias and adverse effects on the results. In this study, preoperative $\mathrm{SCr}$ values were higher in 160 $(160 / 660,24.2 \%)$ patients than after surgery, and only 25 $(25 / 160,15.6 \%)$ of these patients had post-AKI. Thus, instead of focusing on preoperative $\mathrm{SCr}$, postoperative $\mathrm{SCr}$ was selected in our model of risk factors associated with post-AKI. Ultimately, most patients with severe ischemia or malperfusion were not enrolled in this study. The results were appropriate for patients classified as Penn class Aa but are not a guideline to those who are Penn class $\mathrm{Ab}$ and $\mathrm{Ac}$ [22].

\section{Conclusion}

The use of aPRP significantly reduced intraoperative blood transfusions, as well as decreased postoperative mortality-adjusted mechanical ventilation in patients undergoing open repair of acute Type AAD. However, aPRP was independently associated with an increased hazard of post-AKI after adjusting for confounding factors.

\section{Abbreviations}

AAD: Stanford type A acute aortic dissection; aPRP: Autologous platelet-rich plasmapheresis; post-AKI: Postoperative acute kidney injury; CPB: Cardiopulmonary bypass; KDIGO: AKI based on Kidney Disease Improving Global Outcomes; Scr: Serum creatinine; BMI: Body mass index; DM: Diabetes mellitus; LVEF: Left ventricular ejection fraction; LVEDD: Left ventricular end diastolic diameter; EuroSCORE: European system for cardiac operative risk evaluation; MBP: Mean blood pressure; PLC: Platelet count; Hb: Hemoglobin; WBC: White blood cells; Glu: Glucose; LAC: Lactic acid; FIB: Fibrinogen; FDP: Ibrinogen degradation product; APTT: Active part thrombin time; PT: Prothrombin time; APTT: Activated partial thromboplastin time; PTA: Prothrombin activityprothrombin time; ICU: Intensive care unit; CRRT: Continuous renal replacement therapy; AKI: Acute kidney injury;

GI: Gastrointestinal; OR: Odds ratio; Cl: Confidence interval

\section{Acknowledgements}

We thank LetPub (www.letpub.com) for its linguistic assistance during the preparation of this manuscript.

\section{Authors' contributions}

Mu Jin has made contributions to design of the work; Mu Jin, JiaQi Tong, LiangCao and LiWei Liu have made contributions to the acquisition, analysis and interpretation of data; JiaQi Tong, LiangCao, LiuWei Liu and Mu Jin have drafted the work; Mu Jin has substantively revised it. The author(s) read and approved the final manuscript.

\section{Funding}

This work was supported by grants from the Beijing Major Science and Technology Projects from Beijing Municipal Science and Technology Commission (No.Z171100001017083). Sponsors had no influence on the design, analysis, or publication of this study.

\section{Availability of data and materials}

The datasets used and/or analysed during the current study are available from the corresponding author on reasonable request.

\section{Ethics approval and consent to participate}

This study was approved by the Ethics Committee of the Beijing Anzhen Hospital Clinical Research (Beijing, China), and consent was waived because of the retrospective data collection.

\section{Consent for publication \\ Not applicable.}

\section{Competing interests}

The authors declare that they have no competing interests.

\section{Author details \\ 'Department of Anesthesiology, Beijing Friendship Hospital, Capital Medical University, No. 95 Yongan Rd, Xicheng District, Beijing City 100050, China. ${ }^{2}$ Department of Anesthesiology, Beijing Anzhen Hospital, Capital Medical University, Beijing Institute of Heart Lung and Blood Vessel Diseases, and Beijing Engineering Research Center of Vascular Prostheses, No. 2 Anzhen Rd, Beijing 100029, China. ${ }^{3}$ Department of Anesthesiology, Fuwai Hospital, National Center for Cardiovascular Diseases, Peking Union Medical College and Chinese Academy of Medical Sciences, No.167, Beilishi Road, Xicheng District, Beijing 100037, China.}

Received: 27 August 2020 Accepted: 8 December 2020 Published online: 07 January 2021

\section{References}

1. Elsayed RS, Cohen RG, Fleischman F, Bowdish ME. Acute type a aortic dissection. Cardiol Clin. 2017;35:331-45. 
2. Liu Y, Han L, Li J, Gong M, Zhang H, Guan X. Consumption coagulopathy in acute aortic dissection: principles of management. J Cardiothorac Surg. 2017;12:50.

3. Guan XL, Wang XL, Liu YY, Lan F, Gong M, Li HY, et al. Changes in the hemostatic system of patients with acute aortic dissection undergoing aortic arch surgery. Ann Thorac Surg. 2016;101:945-51.

4. Pan X, Lu J, Cheng W, Yang Y, Zhu J, Jin M. Pulmonary static inflation with $50 \%$ xenon attenuates decline in tissue factor in patients undergoing Stanford type a acute aortic dissection repair. J Thoracic Dis. 2018;10:4368-76.

5. Blaudszun G, Butchart A, Klein AA. Blood conservation in cardiac surgery Transfus Med (Oxford, England). 2018;28:168-80.

6. Ferraris VA, Brown JR, Despotis GJ, Hammon JW, Reece TB, Saha SP, et al. 2011 update to the society of thoracic surgeons and the society of cardiovascular anesthesiologists blood conservation clinical practice guidelines. Ann Thorac Surg. 2011;91:944-82

7. Shore-Lesserson L, Baker RA, Ferraris VA, Greilich PE, Fitzgerald D, Roman P, et al. The society of thoracic surgeons, the society of cardiovascular anesthesiologists, and the american society of extracorporeal technology: clinical practice guidelines-anticoagulation during cardiopulmonary bypass. Ann Thorac Surg. 2018;105:650-62.

8. Sandhu HK, Tanaka A, Dahotre S, Charlton-Ouw KM, Miller CC 3rd, Estrera $\mathrm{AL}$, et al. Propensity and impact of autologous platelet rich plasma use in acute type a dissection. J Thorac Cardiovasc Surg. 2020;159(6):2288-2297.e1.

9. Bai SJ, Zeng B, Zhang L, Huang Z. Autologous platelet-rich plasmapheresis in cardiovascular surgery: a narrative review. J Cardiothorac Vasc Anesth. 2020;34(6):1614-21.

10. Zhai Q, Wang Y, Yuan Z, Zhang R, Tian A. Effects of platelet-rich plasmapheresis during cardiovascular surgery: a meta-analysis of randomized controlled clinical trials. J Clin Anesth. 2019;56:88-97.

11. Haase-Fielitz A, Haase M, Bellomo R, Calzavacca P, Spura A, Baraki H, et al. Perioperative hemodynamic instability and fluid overload are associated with increasing acute kidney injury severity and worse outcome after cardiac surgery. Blood Purif. 2017;43:298-308.

12. Kellum JA, Lameire N. Diagnosis, evaluation, and management of acute kidney injury: A kdigo summary (part 1). Crit Care. 2013;17:204.

13. Sun L, Li M, Zhu J, Liu Y, Chang Q, Zheng J, et al. Surgery for patients with marfan syndrome with type a dissection involving the aortic arch using total arch replacement combined with stented elephant trunk implantation: the acute versus the chronic. J Thorac Cardiovasc Surg. 2011;142:e85-91.

14. Sun L, Qi R, Zhu J, Liu Y, Zheng J. Total arch replacement combined with stented elephant trunk implantation: a new "standard" therapy for type a dissection involving repair of the aortic arch? Circulation. 2011;123:971-8.

15. Tian WZ, Er JX, Liu L, Chen QL, Han JG. Effects of autologous platelet rich plasma on intraoperative transfusion and short-term outcomes in total arch replacement (sun's procedure): a prospective, randomized trial. J Cardiothorac Vasc Anesth. 2019;33:2163-9

16. Xu S, Liu J, Li L, Wu Z, Li J, Liu Y, et al. Cardiopulmonary bypass time is an independent risk factor for acute kidney injury in emergent thoracic aortic surgery: a retrospective cohort study. J Cardiothorac Surg. 2019;14:90.

17. Zhou H, Wang G, Yang L, Shi S, Li J, Wang M, et al. Acute kidney injury after total arch replacement combined with frozen elephant trunk implantation: incidence, risk factors, and outcome. J Cardiothorac Vasc Anesth. 2018;32: 2210-7.

18. Wu B, Chen J, Yang Y. Biomarkers of acute kidney injury after cardiac surgery: a narrative review. Biomed Res Int. 2019;2019:7298635.

19. Harky A, Joshi M, Gupta S, Teoh WY, Gatta F, Snosi M. Acute kidney injury associated with cardiac surgery: a comprehensive literature review. Braz J Cardiovasc Surg. 2020;35:211-24.

20. Karkouti K, Wijeysundera DN, Yau TM, Callum JL, Cheng DC, Crowther M, et al. Acute kidney injury after cardiac surgery. Circulation. 2009;119:495-502.

21. Nishigawa K, Fukui T, Uemura K, Takanashi S, Shimokawa T. Preoperative renal malperfusion is an independent predictor for acute kidney injury and operative death but not associated with late mortality after surgery for acute type a aortic dissection. Eur J Cardiothorac Surg. 2020;58(2):302-8.

22. Pisano C, Balistreri CR, Torretta F, Capuccio V, Allegra A, Argano V, et al. Penn classification in acute aortic dissection patients. Acta Cardiol. 2016;71: 235-40.

\section{Publisher's Note}

Springer Nature remains neutral with regard to jurisdictional claims in published maps and institutional affiliations.

\section{Ready to submit your research? Choose BMC and benefit from}

- fast, convenient online submission

- thorough peer review by experienced researchers in your field

- rapid publication on acceptance

- support for research data, including large and complex data types

- gold Open Access which fosters wider collaboration and increased citations

- maximum visibility for your research: over $100 \mathrm{M}$ website views per year

At BMC, research is always in progress.

Learn more biomedcentral.com/submissions 